\title{
BREVE RETROSPECTIVA DO DESENVOLVIMENTO DAS ATIVIDADES DE AUDITORIA NO BRASIL ${ }^{1}$
}

\author{
Álvaro Ricardino \\ Professor Doutor do Curso de Mestrado do Cen- \\ tro Universitário Santo André - SP \\ E-mail: ricardino@fsa.br
}

\author{
L. Nelson Carvalho \\ Professor Doutor do Depto. de Contabilidade e \\ Atuária da FEA-USP - Campus Capital \\ E-mail: Inelson@usp.br
}

\section{RESUMO}

É difícil determinar a exata data em que foi procedido o primeiro trabalho de Auditoria no Brasil, mas, há exatamente um século, o balanço da São Paulo Tramway Light \& Power Co., relativo ao período compreendido entre junho de 1899 e 31 de dezembro de 1902, foi certificado pela empresa canadense de Auditoria Clarkson \& Cross - atualmente Ernst \& Young.

Este artigo procura recuperar a memória desse período, basicamente sob três ângulos: técnicooperacional, acadêmico e legal.

Em termos operacionais, a primeira empresa de Auditoria Independente a se estabelecer no Brasil foi a Deloitte Touche Tohmatsu, que instalou seu primeiro escritório no Rio de Janeiro, em 1911, e o segundo em Recife, em 1917.

Àquela época, o país estava longe de ter qualquer tipo de preocupação com o assunto. Um dos primeiros artigos sobre esse tema foi publicado, em 1928, pela Revista Paulista de Contabilidade, com o título "Contabilidade na Grã-bretanha". O primeiro livro sobre Auditoria foi publicado apenas em 1957 e denominado "Curso de Auditoria".

No que se refere ao aspecto legal, os conceitos e técnicas de auditoria foram formalmente introduzidos no ensino universitário por força do Decreto-Lei 7.988 , de 22 de dezembro de 1945, o qual regulamentava a educação superior nos cursos de Economia, Contabilidade e Ciências Atuariais.

Ainda no âmbito das leis, somente em 1965, pela primeira vez, foi introduzida a figura do Auditor Independente em um diploma legal. Esse foi um marco de enorme importância para a evolução da profissão e das práticas contábeis.

Desde então, tanto as práticas de Auditoria quanto seu ensino acadêmico se consolidaram no país, de forma a atender seu principal objetivo: opinar a respeito da adequação das demonstrações contábeis publicadas, no que diz respeito aos seus aspectos mais relevantes.

Palavras-chave: Auditoria, História da Auditoria no Brasil.

\section{ABSTRACT}

It is hard to determine the exact date of the first auditing work in Brazil but, about one century ago, the balance sheet of the São Paulo Tramway Light \& Power Co., related to the period comprised between June 1899 and December 31 1902, was certified by the Canadian auditors Clarkson \& Cross - now Ernst \& Young.

This paper tries to recover the memory of this period, basically from three perspectives: technical-operational, academic and legal.

In operational terms, the first independent auditing company that settled in Brazil was Deloitte Touche Tohmatsu, which installed its first office in Rio de Janeiro in 1911, and the second in Recife in 1917.

At that time, Brazilian accountants did not even think about this subject. One of the first articles to go into the theme, called "Accounting in Great Britain", was published in 1928 in the Revista Paulista de Contabilidade, known as one of the oldest publications on accounting in the country, since 1922. The first book about auditing was published in Brazil in 1957, named "Course in Auditing".

What the legal aspect is concerned, the teaching of auditing concepts and techniques in higher education courses in accountancy was formally introduced in Brazil by force of Decree-Law ${ }^{\circ} 7.988$, of December $22^{\text {nd }} 1945$, which regulated higher education in Economics, Accountancy and Actuarial Science.

Desde então, tanto as práticas de auditoria quanto seu ensino acadêmico se consolidaram no país, de forma a atender seu principal objetivo: opinar a respeito da adequação das demonstrações contábeis publicadas, no que diz respeito aos seus aspectos mais relevantes.

Also, in legal terms, it was only in 1965 that the figure of Independent Auditor was first introduced into a legal text. This was a landmark for the evolution of the profession and accounting practices.

Since then, both practice and academic teaching of Auditing have become consolidated in the country, in order to fulfill their main role: opining on the adequacy of the published financial statements with respect to their most relevant aspects.

Keywords: Auditing, Brazilian Auditing History. 


\section{INTRODUÇÃO}

Herdeiro de raízes predominantemente latinas, onde vale aquilo que está escrito na lei $^{2}$, o Brasil, desde o início de sua colonização pelos portugueses, por extensão, adotou o sistema jurídico denominado civil law (romano-cristão), o qual, conforme divisão ${ }^{3}$ proposta por David (1978, p. 34), concebe o direito como regras gerais e abstratas de conduta previamente editadas, sistematizadas e racionalizadas em códigos, em que a jurisprudência não deve atuar como fonte criadora de regras de direito, limitando-se a interpretar as leis. Tal orientação transcende o campo jurídico e passa a influenciar diretamente a conduta políticosocial, servindo, ainda, como agente de restrição ou aceleração do desenvolvimento econômico, científico, cultural e tecnológico, apenas para citar alguns.

A Contabilidade e a Auditoria, disciplinas ligadas ao campo social, sofreram as mesmas influências. Não obstante haja um hiato de quase duzentos anos separando a formalização do uso das partidas dobradas na Real Fazenda Portuguesa, através do Alvará de 28 de junho de $1808^{4}$ e a introdução da obrigatoriedade do uso dos serviços de Auditoria Independente, em 14 de junho de $1965^{5}$, em ambos os casos a regulamentação se fez através de diplomas legais. "Em estruturas legais mais voltadas ao modelo de civil law, a contabilidade em geral é regulada direta e legalmente pelo governo central". Lopes (2002, p. 63)

Importante destacar que os usos e costumes antecedem ambas as leis, uma vez que as partidas dobradas já eram utilizadas no Brasil, por volta de 1790 (SÁ, 1980), à época de um movimento revolucionário local denominado "Inconfidência Mineira". No que diz respeito à Auditoria, a legalização se deu após anos de exercício da atividade.

\section{OBJETIVOS E REFERENCIAL TEÓRICO}

Este paperse propõe a atender a dois objetivos: 0 primeiro, de caráter periférico, diz respeito à recuperação da memória de alguns aspectos que marcaram o início das atividades de Auditoria no país e sua influência sobre o ambiente acadêmico e editorial. $O$ segundo objetivo - enfoque central do trabalho - é demonstrar a preponderante influência da legislação na implementação e consolidação formal da profissão, a partir de 1965, uma vez que "até 1964, não havia, no Brasil, uma estrutura legal com a finalidade de regular as atividades desenvolvidas no Mercado de Capitais". Andrezo e Lima (1999, p. 27). A ausência de um mercado de capitais sólido fez com que as empresas operassem "mais com dívidas do que com capital próprio". Andrezo e Lima (op. cit., p. 92).

A necessidade de trazer recursos ao mercado acionário fez com que o governo brasileiro adotasse uma série de medidas institucionais, dentre elas a criação da CVM - Comissão de Valores Mobiliários, autarquia vinculada ao Ministério da Fazenda, formada para disciplinar e estabelecer medidas de atuação no mercado de valores mobiliários. Dentre as suas diversas atribuições encontra-se a competência para disciplinar e fiscalizar as atividades de auditoria das companhias abertas. "Isso possibilita maior fidedignidade das informações e maior segurança dos investidores". Anadrezo e Lima (op. cit., p. 127).

Tais medidas anteciparam alguns referenciais teóricos, tais como: "em situações nas quais predomina o financiamento via mercado de capitais, a evidenciação deve ser mais clara para fornecer informações ao grande número de acionistas que se encontram dispersos no mercado". Lopes (op. cit., p. 64) ou greater disclosure provides information benefits to the stock market. Gelb e Zarowin (2000, p. 1).

\footnotetext{
2 § 2 - "Ninguém será obrigado a fazer ou deixar de fazer alguma coisa, se não em virtude de lei”. Constituição da República Federativa do Brasil, Capítulo dos Direitos e Deveres Individuais e Coletivos, art $5^{\circ}$.

${ }^{3}$ Segundo o autor, os subsistemas de direitos nacionais são: civil law, common law, filosófico-religioso e soviético, este último enfraquecido com a derrocada dos países da cortina de ferro.

4 "I - Para que o método de escrituração e fórmulas de contabilidade da minha Real Fazenda não fique arbitrário e sujeito à maneira de pensar de cada um dos Contadores Gerais, ..., ordeno que a escrituração seja mercantil por partidas dobradas, ...” (Coleção Leis do Brasil, vol. 1, p. 74).

${ }^{5}$ Lei $n^{\circ} 4.728$, de 14 de junho de 1965 .
} 
A importância desta pesquisa está contida nas palavras de Castro (1978, p. 76): "a ciência tem passado, tem história; sem uma idéia do que já aconteceu, do que já se sabe, perde-se a perspectiva".

\section{AS PRIMEIRAS EMPRESAS DE AUDITORIA E A LEGISLAÇÃO PERTINENTE}

Difícil precisar a data do primeiro trabalho de Auditoria no Brasil, mas a primeira evidência concreta da atividade no país pode ser observada no Decreto $\mathrm{n}^{\circ} 2935$, de 16 de junho de 1862, que aprovava a reorganização da Cia. de Navegação por Vapor Bahiana - Anonyma. Àquela época, tanto o empreendimento quanto seus estatutos deveriam ser aprovados por lei. O capítulo XVII, do referido estatuto, denominado "Dos Auditores", dispõe:

$\S 114$ - Eles [os auditores] serão designados pela primeira assembléia ordinária de cada ano.

$\S 116$ - Eles examinarão as contas da Cia. de acordo com as presentes [?]

Infelizmente, não há registros conhecidos sobre os trabalhos executados ou o conteúdo da opinião expressada sobre as contas da empresa. Acredita-se que tais documentos, se existirem, devem estar na Inglaterra já que o empreendimento era constituído, exclusivamente, por capital britânico e o resultado do trabalho dos auditores voltados àqueles acionistas ${ }^{6}$.

O primeiro parecer de Auditoria (conhecido) em território nacional foi emitido há um século. Trata-se do balanço da São Paulo Tramway Light \& Power Co., relativo ao período compreendido entre junho de 1899 (data de fundação da empresa) e 31 de dezembro de 1902, certificado pelos auditores canadenses Clarkson \& Cross atual Ernst \& Young - conforme cópia apresentada a seguir:

\section{AUDITORS' CERTIFICATE.}

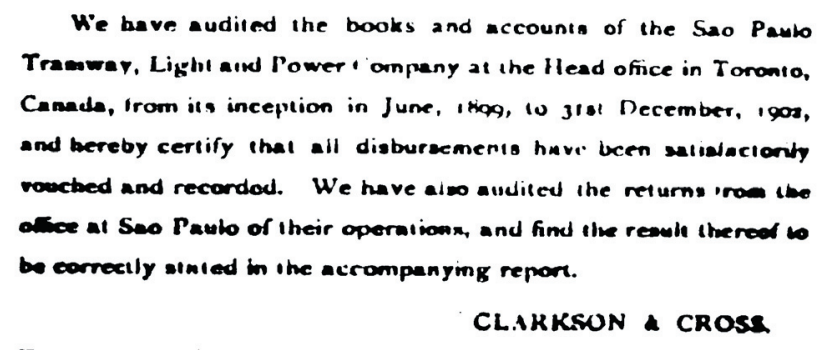

Tomonru, ght April, 1902,

(KANITZ, 1973)

Esse parecer, referente à Auditoria dos livros e das contas da filial brasileira de uma empresa multinacional, expõe uma prática incomum à época. Segundo Franco e Marra (2000, p. 43), "quanto ao efetivo exercício da atividade de Contador como profissional liberal, na qual se incluía a função de auditor independente, pouca coisa existia no Brasil antes de 1931, a não ser os escritórios estrangeiros de auditores, todos de origem inglesa".

Embora os autores não enumerem quais eram esses escritórios, segundo Mills (1996, p. v), a primeira empresa de Auditoria Independente a se instalar no Brasil foi a Price Waterhouse \& Peat Marwick $^{7}$, em 1915. Esse pioneirismo é contestado pelo departamento de comunicações da Deloitte Touche Tohmatsu ${ }^{8}$ que assegura que a empresa instalou seu primeiro escritório no Brasil, na cidade do Rio de Janeiro, em 1911, e o segundo, em Recife, em 1917. Anos mais tarde ingressariam no país outras empresas de grande porte como a Arthur Andersen em 1957, a Arthur \& Young, antecessora da atual Ernest Young, em 1959, apenas para citar as datas de chegada das chamadas Big $5^{9}$ ao Brasil. A experiência adquirida com as empresas estrangeiras levou alguns profissionais egressos delas a fundar as primeiras empresas brasileiras de

\footnotetext{
${ }^{6}$ As informações sobre os estatutos da Cia. de Navegação por Vapor não constam do trabalho original publicado no $3^{\circ}$ Accounting History International Conference por terem sido identificadas em data posterior à publicação do artigo naquele congresso.

${ }^{7}$ Em 1977, Price e Peat cindiram suas atividades. Em 1987, nasceu a KPMG, reunião das empresas Peat Marwick \& Mitchell, a brasileira Robert Dreyfuss e a holandesa Klynveld Main Goerdeler. A respeito desse histórico vide site www.kpmg.com.br.

${ }^{8}$ Acesso pelo site www.deloitte.com.br.

${ }^{9}$ Denominação genérica reservada às cinco maiores empresas de Auditoria Independente em todo o mundo, até 2002. As Big 5 eram assim compostas: Andersen, Delloite Touche Tohmatzu, Ernst \& Young, KPMG, Pricewaterhous \& Coopers.
} 
Auditoria. Desde então, diversas empresas surgiram e prestam seus serviços em todo o território nacional. Conforme exposto no site da CVM - Comissão de Valores Mobiliários, ao final de 2001, havia 301 empresas de auditoria cadastradas naquela instituição.

A instalação dessas empresas no país teve o condão de difundir as práticas de Auditoria em diversos setores, inclusive na administração pública, como demonstra um artigo publicado, em 1934, pela Revista Paulista de Contabilidade:

É obra prima contábil brasileira a organização que deu ao Instituto de Previdência dos Funccionarios Públicos da União a esclarecida intelligencia do grande contabilista e administrador patrício, o sr. Aristides Casado. Do schema de sua formidável organização contábil, destacam-se, ao centro, o contador Geral, commandando um batalhão de sub-contadores; ao seu lado direito destaca-se a secção actuarial, ..., e ao lado esquerdo a secção de auditoria, ...

(SANTOS, 1934, p. 176)

\section{PRIMEIRAS PUBLICAÇÕES SOBRE AUDITORIA NO BRASIL}

Segundo Toledo Filho (op. cit., p. 58), "data de 1957 e denomina-se Curso de Auditoria, o primeiro livro editado no Brasil sobre o assunto". De autoria do Prof. Antônio Lopes de Sá, foi originalmente lançado em dois volumes sendo, também, o primeiro a utilizar o vocábulo "Auditoria" já que, conforme foi assinalado anteriormente, até então a disciplina era denominada "Revisão e Perícia Contábil".

Conquanto seja esse o primeiro trabalho de peso sobre o assunto, o tema não era de todo desconhecido como pode ser comprovado através de um rápido exame dos artigos publicados na Revista Paulista de Contabilidade, conhecida como uma das mais antigas publicações sobre Contabilidade no país ${ }^{10}$, desde 1922.

Um dos primeiros artigos a incursionar pelo tema foi publicado em 1928 e tinha por título "A Contabilidade na Grã-Bretanha”. A matéria, transcrita do anuário da "Camara de Commercio Britannica de São Paulo \& Sul do Brasil", discorria sobre a existência de duas sociedades de contadores naquele país: Institute of Chartered Accountants in England and Wales e a Society of Incorporated Accountants and Auditors, explicando as atividades dos profissionais filiados. Desse texto vale destacar um trecho inovador para a época: "Os auditores são nomeados pelos accionistas, independentemente da Directoria, e compete-lhes examinarem os actos da administração e apresentarem o parecer diretamente aos primeiros" (RPC, 1928, p. 273-6).

Seis anos após, na mesma revista, Furlanetto (1934, p. 8-9), fazia menção à sua "árdua e não curta experiência de auditor" e destacava, em artigo denominado "São Necessários os Auditores?", os benefícios que adviriam aos empresários da época se tomassem a iniciativa de apresentar aos bancos "sem que Ihes fosse solicitado, annualmente, o seu balanço geral acompanhado de minudentes annexos, descriptivos de seu patrimônio, direitos, obrigações e resultados colhidos, cuja exactidão fosse conferida e attestada por auditores".

Em 1940, à véspera do Decreto-Lei 2627 - terceira norma legal a regulamentar as atividades das Sociedades Anônimas no Brasil - podia ser identificada a intenção de alguns renomados contabilistas de fazer constar da referida Lei a obrigatoriedade do exame das Demonstrações Contábeis por contador independente.

Reinach (1940, p. 25-8), em artigo denominado "A Revisão dos Balanços e o Ante-Projéto de Lei de Sociedades Anônimas", propunha, ao então Ministro da Justiça, alterar a redação do art. 128, parágrafo único, pela redação sugerida pelo Instituto Paulista de Contabilidade:

Redação original:

Os fiscais poderão escolher, para acompanhar no exame dos livros, inventários, balanço e contas, um perito-contador, contanto que profissional habilitado, cujos honorários serão fixados pela assembléia geral. (grifo nosso)

Redação formulada pelo Instituto Paulista de Contadores:

Quando a sociedade não mantiver revisão da sua contabilidade, feita por profissionais

${ }^{10}$ Ainda mais antigas são respectivamente: Revista do Grêmio dos Guarda-Livros, do último quarto do século XIX e a Revista Brasileira de Contabilidade, de 1912. 
estranhos ao quadro de pessoal, os fiscais deverão obrigatoriamente escolher um contador ou organização de peritos em contabilidade, para os acompanhar no exame dos livros, inventários, balanços e contas. (grifo nosso)

Tal forma de pensar não era isolada. Um dos maiores, se não o maior nome da Contabilidade brasileira da época, Herrmann Jr. (1946, p. 46), sobre o assunto, assim se manifestou: "É aconselhável que na lei das sociedades anônimas se inscreva um dispositivo tornando compulsória a verificação dos livros por peritos".

A partir da metade dos anos 40 , nota-se uma crescente produção literária sobre o assunto. $O$ enfoque dos diversos artigos elaborados na época ${ }^{11}$ confere aos leitores uma quase catequese em defesa da necessidade dos serviços de Auditoria, embora quase nada houvesse sido publicado a respeito das técnicas de Auditoria.

Foi somente no início da década de 50 que foram publicados os primeiros trabalhos sobre as técnicas de Auditoria e o rol de atividades de seus profissionais. Alguns artigos sobre $\mathrm{o}$ assunto podem ser encontrados na já mencionada Revista Paulista de Contabilidade. Entre eles, destacamos: "Auditoria das Vendas a Prestações" (ANDREUCCI, 1950), "O Auditor nas Grandes Empresas" (NEGRINI, 1956) e "Funções da Auditoria Interna"12 (CAMPÍGLIA, 1957). Neste último, a descrição dos ganhos propiciados pela presença dos auditores na empresa, não obstante beire o exagero, retrata a visão da função na época: "A simples existência de serviços de auditoria externa constitui expectativa capaz de induzir os responsáveis ao bom cumprimento de seus deveres pela certeza de que seus erros, suas negligências ou falhas, serão fatalmente apurados e postos em evidência" (op. cit, p. 4).

Deu-se, também, em 1957, como dito na introdução deste tópico, a publicação, no país, do primeiro livro didático sobre Auditoria, de autoria do Prof. Antônio Lopes de Sá. O autor, no prefácio da obra, informa que o livro foi desenvolvido a partir da reunião e compilação de diversas obras sobre o assunto publicadas principalmente nos Estados Unidos da América, Inglaterra, Argentina e Cuba. Dentre as obras referenciadas as mais utilizadas são:
- ARTHUR W. Holmes. Auditing, principles and procedure, 4. ed. Homewood, R.D. Irwin, Inc., 1956.

- BELL, William H. e JOHNS, Ralph S. Intervención y Fiscalización de Contabilidades, 2. ed., vol. 1. Tradução LOPEZ-HIDALGO, Orlando, Nova York, 1942.

- BENNETT, R. J., NASMYTH, J., CHASE, S. Curso Completo de Auditoria, Tradução LOPEZ-HIDALGO, Olivério, Havana, 1942.

- JOAQUIM, Raul, CATELLA, S. E. Jorge. Tratado de Auditoria, vol. 1, Buenos Aires, 1947.

Ainda sobre a obra de Sá (1957), vale mencionar seu conteúdo, voltado mais para conceituação e planejamento dos trabalhos do que para as técnicas de Auditoria propriamente ditas, até porque eram bastante elementares àquela época, concentradas fundamentalmente em testes de exatidão aritmética, na conferência documental, por amostragem, das transações efetuadas e na propriedade, e de seus registros. As "normas técnicas" da época se restringiam a:

a. Comparação das demonstrações contábeis com os registros de Contabilidade, acrescidos de provas parciais e seletivas destes últimos com a documentação e testes de exatidão aritmética.

b. Leitura dos principais contratos e documentos da empresa, tais como: livros de ata, contrato social, razão de acionistas, razão de bancos, de caixa, de clientes, de custos, de fornecedores, de filiais, de mão de obra, de vendas e outros.

Nos dizeres do próprio autor:

Devem ser observados, sejam quais forem as verificações, os seguintes princípios gerais:

1. Observar se todos os registros do exercício foram feitos;

2. Verificar se não existem registros de fatos que dizem respeito a exercícios anteriores novamente escriturados no exercício que se examina;

3. Examinar se os saldos de abertura são idênticos aos de encerramento;

4. Ver se os transportes são feitos corretamente;

5. Confrontar um registro com os dados da escrita de terceiros (extratos de bancos, de fornecedores, etc.).

(SÁ, 1957, p. 237)

\footnotetext{
${ }^{11}$ A este respeito vide (FRANZOLIN, 1946), (CAMPOS, set. 1947), (CAMPOS, out. 1947), (PFALTZGRAFF, 1948).

${ }^{12}$ Por um erro de impressão, foi publicado "Funções de Auditoria Interna". O correto seria "Funções da Auditoria Externa", já que é este o mote do artigo.
} 
Não obstante o grau primário dos métodos da época, o livro de Sá deve ser entendido como um marco, vis-à-vis o programa de ensino da disciplina AUDITORIA nos cursos de Ciências Contábeis na mesma ocasião.

O início dos anos 60 daria início a uma produção literária mais profícua e consistente. A Revista Paulista de Contabilidade instituiria, em 1962, uma seção mensal voltada à Auditoria Contábil tendo como responsável o Prof. Ernesto Marra.

No segundo número da referida seção, um artigo denominado "O Parecer do Auditor" traz a público um trabalho desenvolvido pelo Instituto dos Contadores Públicos de São Paulo, o qual viria a se constituir no primeiro modelo de parecer-padrão adotado no Brasil. Inspirado nos padrões utilizados pelas empresas de Auditoria americanas, possuía a seguinte redação:

\section{PARECER DOS AUDITORES}

Examinamos o balanço geral da ................. encerrado em ................, e a demonstração de lucros e perdas correspondente ao findo na citada data. O exame obedeceu aos padrões usuais de auditoria e incluiu as verificações que julgamos adequadas. Em nossa opinião, o balanço geral e a demonstração de lucros e perdas refletem com propriedade a situação patrimonial e financeira da em ................... e o resultado econômico do findo naquela data, de acordo com os preceitos de Contabilidade geralmente aceitos, aplicados com uniformidade em relação ao .......... anterior. ......., de .......... de 19.. (MARRA, 1962 a, p. 7)

No mês seguinte, Marra (1962, p. 7) publicaria, na já mencionada seção, um artigo denominado "Normas Técnicas de Auditoria" no qual expunha "certas normas mínimas que devem ser observadas, sendo indispensável que o auditor se assegure de que o seu exame as tenha abrangido". Referia-se ele às recomendações adotadas pela IV Conferência Interamericana de Contabilidade, realizada em Santiago do Chile, naquele mesmo ano. (MARRA, 1962 b, p. 7)

Nos anos seguintes, o tema Auditoria ganharia novos adeptos que defenderiam a necessidade de normalização da atividade. Finalmente, em novembro de 1966, as normas de Auditoria viriam a ser definidas pelo Instituto dos Contadores Públicos do Brasil, as quais, conforme Schwacke (1970, p. 35), "em muitos aspectos se assemeIham às contidas no pronunciamento de número 33 do AICPA.

Basicamente, as Normas de Auditoria subdividiam-se em três tópicos:

I. Normas Relativas à Pessoa do Auditor;

II. Normas Relativas à Execução dos Trabalhos e

III. Normas Relativas ao Parecer.

Importante mencionar que, dentre as diversas e significativas mudanças introduzidas nas referidas normas, uma limitação significativa pairava sobre elas e dizia respeito à ausência de Preceitos de Contabilidade Geralmente Aceitos. Para melhor compreensão da extensão do problema, serão reproduzidos, a seguir, os tópicos 15 e 16 retro mencionados:

15. Assim, é indispensável que o auditor proceda ao exame, na extensão necessária, para certificar-se de que as demonstrações contábeis foram calcadas em preceitos de contabilidade geralmente aceitos.

16. Enquanto o Instituto dos Contadores Públicos do Brasil não codificar os preceitos de contabilidade geralmente aceitos no Brasil, os membros deste Instituto aceitam como tais os preceitos contidos nas obras de doutrinadores consagrados e os constantes do "currículo" das disciplinas de Contabilidade das faculdades de Ciências Contábeis, reconhecidas oficialmente pelos poderes constituídos.

Anos mais tarde, o mesmo assunto seria objeto de amplos estudos por parte do Conselho Federal de Contabilidade e culminaria com a edição, em 23 de outubro de 1981, da Resolução CFC $n^{\circ}$ 529/81 que dispunha sobre as Normas Brasileiras de Contabilidade e, na mesma data, pela Resolução CFC $n^{\circ} 530 / 81$, que aprovava os Princípios Fundamentais de Contabilidade, Norma NBC T 1 (CFC, 2000, p. 22).

O período compreendido entre 1967 e 1972 foi marcado por artigos que consolidavam o exercício da atividade, tais como os publicados por Franco (1967, p.3-8; e 1968, p.3-5). Caracterizavam-se por marcar posições quanto ao direito do exercício da atividade ser de competência exclusiva dos bacharéis em ciências contábeis, enquanto que outros 
pugnavam pela definição da responsabilidade legal do auditor. Exemplificam tais casos os artigos escritos por Mussolini (1971, p.1; e 1972, p. 19-20), e ainda Lattorraca (1970, p. 3).

A leitura atenta dos artigos desse período revela visíveis mudanças conceituais relativas à função dos auditores, bem diferentes daquelas indicadas por Campiglia (1957, p. 9), citadas anteriormente. Um exemplo de tais mudanças pode ser verificado no texto a seguir:

Não raro, também, presumem muitos que a Auditoria tem por finalidade a investigação de fraudes e desfalques. Nada mais errôneo do que esse entendimento.

O descobrimento de fraudes já foi o propósito primário da auditoria; todavia, com o desenvolvimento econômico, o vulto dos negócios e o número de transações cresceram tanto que esse propósito se tornou menos importante comparado com a opinião sobre as demonstrações financeiras, consideradas em seu conjunto.

(Lattorraca, 1970, p. 3)

Em 1973, o Prof. Stephen Kanitz publicava um livro denominado "Análise do Parecer do Auditor", uma das primeiras obras brasileiras a tratar o tema com maior profundidade.

Após a edição da Lei 6.404/76, que estabelecia a obrigatoriedade de Auditoria Independente para as Companhias Abertas e impunha obediência aos princípios contábeis na escrituração das companhias, a produção literária, em torno do tema, ganhou significativo impulso, trazendo a público expressivo volume de obras nacionais e internacionais.

\section{INÍCIO E DESENVOLVIMENTO DO ENSINO DA DISCIPLINA AUDITORIA NOS CURSOS DE GRADUAÇÃO EM CIÊNCIAS CONTÁBEIS}

Conforme compilação efetuada por Bueno (1964, p. 135-6), o ensino dos conceitos e técnicas de auditoria nos cursos superiores de Ciências Contábeis foi formalmente introduzido em nosso país por força do Decreto-Lei $n^{\circ} 7.988$, de 22 de setembro de 1945, que dispunha sobre o ensino superior de Ciências Econômicas e de Ciências Contábeis e Atuariais. O Artigo $3^{\circ}$ indicava que o curso de Ciências Contábeis teria quatro anos e que, dentre suas disciplinas incluía-se uma denominada "Revisões e Perícia Contábil".

A substituição da denominação "Auditoria" por "Revisões e Perícia Contábil" devia-se ao elevado grau de xenofobia da época, conforme pode ser depreendido do texto a seguir:

A recente reforma do ensino comercial, que elevou ao grau universitário o estudo das ciências contábeis e atuariais introduziu, no programa desse curso, uma cátedra de "Revisão e Perícia Contábil", destinada, praticamente ao estudo teórico e prático da Auditoria. Si os puristas consideram o uso desse termo um barbarismo indesculpável, (grifo nosso) por outro lado somos forçados ... a adaptar à nossa língua as expressões utilizadas por esses predecessores.

(FRANZOLIM, 1946, p. 9)

O curso de Contabilidade da Faculdade de Ciências Econômicas e Administrativas da Universidade de São Paulo, em 1950, oferece um bom exemplo do conteúdo básico dessa disciplina àquela época:

\section{I - PARTE PRELIMINAR}

Funções Contábeis

1. Conceito de Contabilidade e suas Funções.

2. Revisão e Perícia. Suas Distinções.

3. Especialização Profissional.

\section{II - PARTE FUNDAMENTAL}

1 - FUNÇÃO REVISORA

\section{Conceituação}

4. Autenticação, Certificação, Inspeção.

5. Exame, Crítica, Informação.

\section{Esquema Funcional}

6. Técnica Profissional.

7. Finalidades da Revisão.

\section{Objeto, Método, Efeitos}

8. Organização de Contabilidade. Formas Expositivas.

9. Elementos Patrimoniais. Contas de Resultado.

10. Esquema de Trabalho. Fase Precatória, Fase Executiva. Conclusões.

11. Efeitos Materiais e Morais. 
2 - Função Pericial

Conceituação

12. Exame Pericial. Vistoria. Louvação. Arbitragem.

13. Quesitos. Laudos. Relatórios.

\section{Esquema Funcional}

14.Técnica Profissional.

15. Finalidades Periciais.

\section{Objeto, Método, Efeitos}

16. Classificação e estudo particularizados dos principais casos de perícia.

17. Esquemas de Trabalho. Fase Preparatória. Fase Executiva. Conclusões.

18. Efeitos Materiais e Morais, Legais e Sociais.

\section{a) Seminário \\ 19. Prática de Revisão. \\ 20. Prática de Perícia.}

A primeira reestruturação de porte no conteúdo programático dos cursos de Ciências Contábeis deuse em 1963, através da Resolução $S / N$, de 08 de fevereiro de 1963. A Resolução tinha por objetivo fixar o currículo mínimo e a duração dos cursos de Ciências Atuariais, Ciências Contábeis e Ciências Econômicas. Dentre as disciplinas que integravam o "Ciclo de Formação Profissional" incluía-se a "Auditoria e Análise de Balanços".

Quase trinta anos depois, o Conselho Federal de Educação, através da Resolução $n^{\circ} 3$, de 5 de outubro de 1992, voltaria a promover nova alteração no conteúdo mínimo e na duração do curso de graduação em Ciências Contábeis. A categoria II, destinada a descrever os conhecimentos necessários à formação profissional, mantinha a disciplina "Auditoria" entre aquelas indicadas como de conhecimento obrigatório.

Novas mudanças viriam em 2002 através do Parecer CES/CNE N $N^{\circ}$ 0146/2002. Os aspectos mais substanciais das mudanças propostas dizem respeito à liberdade de programação curricular atribuída às instituições de ensino.

No que diz respeito especificamente ao Curso de Graduação em Ciências Contábeis, único habilitado a ministrar a disciplina Auditoria, o Parecer $N^{\circ}$ 0167/2002 declina, em seu item II:

Conteúdos de Formação profissional: altera a redação anterior indicando "estudos específicos atinentes às Teorias da Contabilidade, além de suas relações com a Atuária, Auditoria, Controladoria e suas aplicações peculiares ao setor público e privado".

\section{A INFLUÊNCIA DA LEGISLAÇÃO NO DESENVOLVIMENTO DAS ATIVIDADES DE AUDITORIA NO BRASIL.}

Até os anos 50, o Brasil carecia de uma infraestrutura de mercado que permitisse alavancar seu processo industrial. Em 1952, o governo criou o BNDES - Banco Nacional de Desenvolvimento Econômico e Social cujo capital foi obtido com a elevação, em 10\%, da alíquota do imposto de renda das pessoas físicas. Ainda naquela década as indústrias multinacionais, notadamente na área automobilística, começaram a se fixar no país. O Brasil vivia "os anos de ouro do governo JK'13". O PIB brasileiro, entre 1957 e 1961, indicava um crescimento superior a $8 \%$ ao ano.

O final desse período, que se caracterizou pela construção de uma nova cidade para servir de capital do país (Brasília), marcou o início de um período de recessão, motivado pelo alto grau de endividamento e inflação. O país necessitava urgentemente criar mecanismos para a solução desses problemas. Uma das respostas possíveis era a melhoria do mercado de capitais.

Segundo Andrezo e Lima (1999, p. 49) "o Mercado de Capitais teve pouca importância na economia [brasileira] até meados dos anos 60, embora já existissem Bolsas de Valores no Rio de Janeiro e São Paulo, criadas no século XIX...". Em 1965, a Lei $n^{\circ} 4728$ passou a ser o estatuto básico do Mercado de Capitais brasileiro. Nela foram reunidos os dispositivos legais existentes, até então, acrescidos de regras que procuravam revitalizar o mercado. Um dos itens que compunham a exposição de motivos da lei indicava o "estabelecimento de padrões de conduta para os participantes do mercado de capitais, pois este é naturalmente sensível à confiança do público" ${ }^{14}$.

\footnotetext{
${ }^{13}$ Presidente do Brasil entre 1956 e 1961.

${ }^{14} \mathrm{O}$ grifo não consta do original.
} 
Pela primeira vez, um texto legal introduzia no país a figura do Auditor Independente:

Art. 20. Compete ao Conselho Monetário Nacional expedir normas a serem observadas pelas pessoas jurídicas referidas neste artigo, e relativas a:

b) Organização do balanço e das demonstrações de resultados, padrão de organização contábil, relatórios e pareceres de auditores independentes registrados no Banco Central.

A Lei 4728/65 criou, ainda, os Bancos de Investimentos que teriam suas atividades regulamentadas no ano seguinte, assim como as Bolsas de Valores e as Sociedades Corretoras e Distribuidoras de Títulos e Valores Mobiliários. Nesse mesmo período, o Banco Central do Brasil definiu as Sociedades Anônimas de Capital Aberto, incentivando o registro de companhias na Bolsa. As 289 Sociedades Anônimas de Capital Aberto, registradas no Banco Central do Brasil, em 1968, passaram para 493, em 1971.

No mesmo ano viria a regulamentação das atividades dos auditores. (Resolução $\mathrm{CMN} \mathrm{n}^{\circ} 7$ ) Posteriormente, outros dispositivos legais reforçariam sua atuação:

- Resolução $n^{\circ}$ 39, de 20.5.66. Estabelece a AUDITORIA obrigatória para as Bolsas de Valores e determina que estas fiscalizem seus associados através de AUDITORES;

- Resolução $n^{\circ}$ 88, de 30.1.68. Estabelece a necessidade de PARECER DE AUDITOR INDEPENDENTE como documento que deve acompanhar o pedido de registro de sociedades que pretendam negociar os títulos por elas emitidos no mercado de capitais.

A regulamentação do mercado de capitais e a fixação de seus instrumentos de controle coincidem com um período de grande crescimento na economia brasileira. Nunca em sua história o investidor brasileiro havia se interessado tanto pelo mercado acionário como em 1971, mas, a partir de julho daquele ano, o preço das ações começou a cair verticalmente, reduzindo substancialmente o volume de negócios. Demoraria muitos anos até que essa fase depressiva fosse superada. ...quando ocorreu a baixa, os investidores desapareceram, o que deixou claro que eles ainda não tinham maturidade para atuar no mercado financeiro e as Bolsas de valores e os órgãos reguladores ainda não tinham estrutura suficiente para suportar volumes tão grandes de negociações, além de existirem falhas na legislação.

Andrezo e Lima (op. cit., p. 82)

O desastre da experiência inicial levou à criação de novos mecanismos legais para corrigir as distorções do passado e tentar reaproximar os investidores. Dentre eles os mais significativos foram:

- Resolução $n^{\circ}$ 220, de 10.5.72. Institui AUDITORIA obrigatória para as sociedades anônimas registradas no Banco Central que tenham suas ações cotadas no mercado de capitais. Disciplina o registro dos AUDITORES INDEPENDENTES.

- Resolução CFC n ${ }^{\circ} 321$, de 14.04.72. Determinaria o padrão de redação para o primeiro parecer de auditoria adotado no Brasil ${ }^{15}$, tomando por base a redação do parecer recomendado pelo AICPA - American Institute of Certified Public Accountants, elaborado em 1948.

- Circulares 178 e 179, de 11.05.1972, editadas pelo BACEN - Banco Central do Brasil. Determina a formalização legal das atividades dos auditores independentes, regulamentando o Registro de Auditores Independentes e baixando Normas Gerais de Auditoria e Princípios e Normas Gerais de Contabilidade. Nelas ficavam estabelecidos:

Os critérios de escrituração e contabilização das receitas, custos, despesas, bens destinados à exploração do objeto social, depreciação, mercadorias, matérias-primas, bens destinados à alienação, direitos e patentes industriais, direitos de utilização de obra de autor, direitos de concessão e marcas de fábrica ou semelhantes, ações e os títulos de renda fixa, créditos a receber e de liquidação duvidosa, Fundo de Comércio, despesas diferidas, investimentos em empresas coligadas, subsidiárias

${ }^{15}$ Para informações adicionais sobre a evolução do texto do Parecer dos Auditores, o significado das alterações havidas desde então, bem como a análise das limitações ao seu poder de comunicação, vide Carvalho (1989). 
ou dependentes, direitos e responsabilidades contingentes ou eventuais tais como avais, fianças, demandas judiciais e contratos onerosos a serem cumpridos e os demais direitos, obrigações e situações que ainda não façam parte do patrimônio, mas que imediata ou remotamente possam vir a afetá-lo positiva ou negativamente. Também foram determinados os critérios gerais para a Formação de Reservas e Provisões, para classificação do Balanço Patrimonial e para a apresentação gráfica do Balanço Patrimonial e Demonstrativo de Resultados.

(ANDREZO E LIMA, 1999, p. 90)

A reprodução desse extenso texto tem por objetivo trazer à memória a insipiência dos padrões e demonstrações contábeis vigentes até então, os quais, como conseqüência, faziam com que o exercício das atividades de auditoria em nosso país estivesse limitado a situações mais ou menos pontuais.

A partir dessas Resoluções e Circulares, a Auditoria Independente institucionalizou-se no Brasil. O aumento do número de Sociedades Anônimas que recorreram ao mercado de capitais expandiu as empresas de Auditoria até então existentes e fez surgir diversas outras de maior ou menor porte. Desde então, diversos outros atos regulatórios ou diplomas legais foram editados, dos quais destacam-se os seguintes:

- Lei $n^{\circ}$ 6.385, de 7.12.76. Cria a Comissão de Valores Mobiliários (CVM) ${ }^{16}$ e estabelece que cabe à mesma registrar e fiscalizar os Auditores Independentes, habilitando-os a AUDITAR as companhias abertas e as sociedades integradas do sistema de distribuição e intermediação de valores mobiliários. Estabelece, ainda, a responsabilidade civil do Auditor Independente;

- Lei 6.404, de 15.12.76. (Lei das Sociedades Anônimas). Estabelece a obrigatoriedade de Auditoria Independente para as Companhias Abertas e para as demonstrações contábeis de grupos de sociedades que inclua companhia aberta. Baixa normas contábeis e impõe a obediência aos princípios contábeis na escrituração das companhias;
- Lei $n^{\circ} 7492$, de 16.06.86. (Lei do Colarinho Branco). Define os crimes contra o Sistema Financeiro Nacional. "Esta lei representava velha aspiração das autoridades e do povo no sentido de reprimir com energia as constantes fraudes observadas no Sistema Financeiro nacional, especialmente no mercado de títulos e valores mobiliários". Andrezo e Lima (op. cit., p. 170)

- Resolução n 829 , de 17.12.97, do Conselho Federal de Contabilidade. Aprova a NBC T 11 - Normas de Auditoria Independente das Demonstrações Contábeis.

$\mathrm{Na}$ década de noventa, mais precisamente ao final de 1995 e início de 1996, três episódios relacionados a incorreções das demonstrações contábeis, desgastaram a imagem de três das principais empresas de auditoria em atividade no país: referimo-nos aos acontecimentos que envolveram os Bancos Econômico, Noroeste e Nacional, auditados respectivamente pela Ernst \& Young, Price Waterhouse e KPMG. Não é objetivo deste trabalho explanar as circunstâncias que envolveram essas seis entidades ${ }^{17}$. Vale, isto sim, mencionar que, na tentativa de minimizar ocorrências futuras de caráter similar, o Banco Central do Brasil - BACEN, adotou algumas medidas relacionadas à atividade de auditoria, a saber:

- Resolução n².267, de 29.03.96 - dispõe sobre a auditoria independente das instituições financeiras, demais entidades autorizadas a funcionar pelo Banco Central do Brasil, fundos de investimentos constituídos nas modalidades regulamentadas pelo referido Órgão e administradoras de consórcio;

- Circular n².676, de 10.04.96 - estabelece normas complementares àquelas fixadas na Resolução n 2.267/96;

- Lei n 9613, de 03.03.1998 - dispõe sobre os crimes de lavagem ou ocultação de bens.

Desde então, outras normas vêm sendo criadas visando o aperfeiçoamento concomitante das práticas contábeis e de Auditoria no país.

As causas que levam à estruturação tão recente desse mercado, - menos de quarenta anos - assim

\footnotetext{
${ }^{16}$ Organismo equivalente à SEC - Security Exchange Commission, nos EUA.

${ }^{17}$ Sobre o assunto vide Antunes (1998).
} 
como dos instrumentos que Ihes dão confiabilidade, são múltiplas e vão da cultura à ética, passando por aspectos sócio-econômicos e legais. Conhece-las, ainda que brevemente, é fundamental para sua compreensão.

Desde sua origem até 1822, quando deixou de ser colônia portuguesa, o Brasil teve seu desenvolvimento econômico fundamentado no extrativismo e, posteriormente, na agricultura. As atividades industriais, ao longo do século XIX e metade do século $X X$, foram poucas e normalmente tímidas. O perfil da estrutura acionária de tais empreendimentos se caracterizava pela concentração de ações nas mãos de poucos, sendo que, muitas vezes, o próprio Estado era o acionista controlador. Nesse modelo, (stakeholders) os principais acionistas estão dentro da própria empresa, o que leva à assimetria das informações contábeis, ou seja, o público externo, normalmente os acionistas minoritários, têm acesso somente às informações publicadas. Tal característica pode desestimular investimentos nesse mercado, já que a relevância dos números contábeis tende a ser maior em países que apresentam duas características ${ }^{18}$ :

- predominância de financiamentos por meio de mercado de capitais;

- acesso restrito a informações privilegiadas.

Não se pode afirmar, mesmo nos dias de hoje, que seja essa a tônica dos investimentos no Brasil.

Adicionalmente, o modelo legal do país (civil law), mencionado no início deste trabalho, adiciona outros ingredientes às dificuldades do mercado de capitais, pois condiciona seu funcionamento a regras detalhadamente explicitadas em lei, o que, muitas vezes, engessa o próprio mercado.

Anderson, apud Lopes (2002, p. 79) reúne e sintetiza esse conjunto de características com a seguinte explanação:

Brazil's institutions are far from primitive, but they appear insufficiently developed to substantially assist parties to financial contracts. First, Brazil has a civil-law legal tradition, characterized ... as an impediment to external financing in general. The Brazilian legal system, in particular, does not imply the principle of stare decisis and judiciary is regarded as inefficient and sometimes corrupt. Second, the quality of diclosure by Brazilian firm is perceived to be low. South American accounting practices are dominated by the legal and administrative systems inherited from Iberian colonizers and the 'highly political environment that result from such systems'. Third, ancillary, disclosure institutions are weak. Fourth, thin trading and volatile pricing characterize Brazilian financial markets. Finally, Brazilian regulators do not provide the same guarantee of financialsystem soundness as that enjoyed in developed countries.

\section{CONCLUSÃO}

A atividade de Auditoria se faz presente no Brasil há, pelo menos, um século, embora em função das características legalistas do país, sua prática somente tenha sido regulamentada a partir de 1965. Antecipando uma tendência que viria a se consolidar nos anos seguintes, profissionais de Contabilidade e acadêmicos, começaram a publicar os primeiros ensaios sobre o assunto, desde 1928. No ambiente acadêmico, a disciplina Auditoria, inicialmente denominada Revisão e Perícia Contábil, foi introduzida oficialmente nos currículos dos Cursos Superiores de Ciências Contábeis, a partir de 1945, reconhecendo a necessidade de transmitir aos seus alunos uma atividade que o mercado vinha praticando, há algum tempo, ainda que de forma tímida e não regulamentada.

Observada sob a perspectiva de uma fundamentação teórica, a introdução e evolução histórica dos conceitos e práticas de Auditoria no Brasil indicam uma ampla relação entre o comportamento da curva de atividade econômica e o ciclo dos grandes empreendimentos no país. Ainda que analisado de forma sumária, o relato sintético oferecido neste estudo permite observar que a primeira grande influência nas origens da atividade de Auditoria no Brasil tem início nos estatutos de companhias estrangeiras, notadamente inglesas, que

${ }^{18}$ Lopes (2002, p. 65). 
se fixaram no país após a segunda metade do século XIX. Infelizmente, salvo o texto do estatuto, não são conhecidas provas documentais da realização efetiva de tais trabalhos.

A primeira evidência documental conhecida de um trabalho de Auditoria no Brasil data do início do século XX e diz respeito ao parecer dos auditores da Cia. São Paulo Tramway Light \& Power Co., relativo ao período compreendido entre junho de 1899 (data de fundação da empresa) e 31 de dezembro de 1902.

Outro aspecto especialmente notável nas relações entre a história econômica e o desenvolvimento da Auditoria no Brasil se observa na crescente presença de capital de risco estrangeiro no país. Nesse sentido, deve ser dado especial destaque para os anos 50 , durante a chamada "industrialização da era JK" que efetivamente marcou a fixação de empreendimentos multinacionais no país, notadamente aqueles representantes da indústria automobilística. Tal presença deu motivo a discussões mais profundas sobre a Contabilidade Gerencial (técnicas para mensurar a gerência), Contabilidade Financeira (técnicas para evidenciar o resultado de ações gerenciais) e, conseqüentemente, técnicas de Auditoria.
O marco mais significativo da regulação da atividade somente ocorreria a partir de 1965 e seria fortalecido em 1976, quando da criação da CVM - Comissão de Valores Mobiliários - com a função de registrar e fiscalizar Auditores Independentes, capacitando-os a realizar Auditoria em sociedades e corretores e negociadores de valores mobiliários. No mesmo ano, a Lei 6.404 - Lei das Sociedades por Ações - estabeleceu a obrigatoriedade da Auditoria Independente para as Sociedades e as demonstrações contábeis de grupos que incluem sociedades. Posteriormente, em 1997, a Resolução n 829, do Conselho Federal de Contabilidade, aprovou NBC T 11 Padrões para a Auditoria Independente das Demonstrações Contábeis.

Desde então, tanto o exercício da Auditoria quanto o ensino acadêmico da disciplina se consolidaram no país cumprindo seus respectivos papeis: o primeiro, o de se pronunciar sobre a adequação das demonstrações contábeis publicadas, no que diz respeito aos seus aspectos mais relevantes. O segundo, procurando ensinar aos nossos universitários os fundamentos e técnicas utilizadas no exercício da profissão.

\section{REFERÊNCIAS BIBLIOGRÁFICAS}

ANDREUCCI, Bruno Pedro. Auditoria das Vendas a Prestação. Revista Paulista de Contabilidade, v. 317, p. 36-9, nov, 1950.

ANDREZO, A.F. e LIMA, I. S. Mercado Financeiro - aspectos históricos e conceituais, FIPECAFI/USP. São Paulo: Pioneira, 1999.

ANTUNES, Jerônimo. Contribuição ao Estudo da Avaliação de Risco e Controles Internos na Auditoria de Demonstrações Contábeis no Brasil. 1998. Dissertação. (Mestrado em Controladoria e Contabilidade) - Faculdade de Economia, Administração e Contabilidade, Universidade de São Paulo.

BUENO, Luiz de Freitas, Coletânea de Legislação do Interesse das Faculdades de Ciências Econômicas. São Paulo: Tomo II, Legislação Federal, 1964.

CAMPÍGLIA, Américo Oswaldo. Funções da Auditoria Interna, Revista Paulista de Contabilidade, v. 378, p. 4-11, nov/dez, 1957.

CAMPOS, Eduardo Sampaio. Não Preciso de Auditores. Revista Paulista de Contabilidade, v. 280, p. 27, out, 1947.

Auditoria Independente. Revista Paulista de Contabilidade, v. 279, p. 6-7, set, 1947.
CARVALHO, Luiz Nelson Guedes de. O Parecer dos Auditores Independentes sobre Demonstrações Contábeis no Brasil: estudo das limitações ao seu poder de comunicação. 1989. Dissertação. (Mestrado em Controladoria e Contabilidade) - Faculdade de Economia, Administração e Contabilidade da Universidade de São Paulo, São Paulo.

CASTRO, Cláudio de Moura. A Prática da Pesquisa. São Paulo: McGraw-Hill do Brasil, 1978.

COLEÇÃO LEIS DO BRASIL, Rio de Janeiro, Imprensa Nacional. CONSELHO FEDERAL DE CONTABILIDADE, Princípios Fundamentais de Contabilidade e Normas Brasileiras de Contabilidade, 2. ed. Brasília: CFC, 2000.

DAVID, René. Os Grandes Sistemas do Direito Contemporâneo: direito comparado. 2 ed. Trad. Hermínio A. de Carvalho. Lisboa: Meridiano, 1978.

DEVEZA, G. A., A Contabilidade no Brasil Antigo. Revista Paulista de Contabilidade, v. 218, p.11-5, ago. 1942.

ERNST \& YOUNG, SOTEC, Relatórios e Pareceres de Auditoria, Curso Básico de Auditoria - normas e procedimentos, São Paulo: Atlas, 1966. 
FRANCO, Hilário e MARRA, Ernesto. Auditoria Contábil. 3 ed. São Paulo: Atlas, 2000.

FRANCO, Hilário. Condições para o Exercício da Auditoria Externa. Revista Paulista de Contabilidade, n 422, 1968.

Formas de Auditoria. Revista Paulista de Contabilidade, $\mathrm{n}^{\circ} 421,1967$.

FRANZOLIM, Mário. Auditoria - Uma Real Oportunidade. Revista Paulista de Contabilidade, v. 264, p. 9-11, jun, 1946.

FURLANETTO, Américo F. São Necessários os Auditores? Revista Paulista de Contabilidade, v. 115/116, pp. 8-9, jan/fev, 1934.

GELB, D., ZAROWIN, P. Corporate Disclosure Policy and the Informativeness of stock Prices, Working Paper, New York University, N.Y., 2000. Disponível em: <http://papers.ssrn.com/ sol3/papers.cfm?abstract_id=235009\#PaperDownload $>$.

HERRMANN Jr, Frederico. Padronização dos Balanços das Sociedades Anônimas. São Paulo: Atlas, 1946.

KANITZ, Sthefen, Análise do parecer do Auditor. São Paulo: Atlas, 1973.

LATTORRACA, Nilton. A Responsabilidade do Auditor. Revista Paulista de Contabilidade, $\mathrm{n}^{\circ}$ 433, 1970.

LOPES, Alexsandro Broedel. A Informação Contábil e o Mercado de Capitais. São Paulo: Pioneira Thomson Learning, 2002.

LOPES DE SÁ, A. Aspectos Contábeis da Inconfidência Mineira, Ouro Preto, Ministério da Fazenda - Escola de Administração Fazendária, 1980.

Curso de Auditoria. São Paulo: Atlas, 1957.

MARRA, Ernesto. Normas Técnicas de Auditoria. Revista Paulista de Contabilidade, v. 400, p. 7, mar, 1962 b.
O Parecer do Auditor. Revista Paulista de Contabilidade, v. 399, p. 7, fev, 1962 a.

MILLS, John R., Charles William Miller 1894 - 1994, Memoriam S.P.A.C., Price Waterhouse, 1996.

MUSSOLINI, Luiz Fernado. Auditoria por Contadores - Vitória da Lei e do Bom Senso. Revista Paulista de Contabilidade, $\mathrm{n}^{\circ} 438,1972$.

Os Auditores Independentes e o Banco Central do Brasil. Revista Paulista de Contabilidade, $\mathrm{n}^{\circ}$ 434, 1971.

NEGRINI, Antenor Silva. O Auditor nas Grandes Empresas. Revista Paulista de Contabilidade, v. 368, p. 10-2, mar/abr, 1956.

PFALTZGRAFF, Rogério. A Importância da Auditoria. Revista Paulista de Contabilidade, v. 292, p. 11-2, out, 1948.

REINACH, Heinrich. A Revisão dos Balanços e o Ante-Projeto de Lei de Sociedades Anônimas. Revista Paulista de Contabilidade, v. 188, p. 25-9, fev, 1940.

REVISTA PAULISTA DE CONTABILIDADE. São Paulo, n. 53/ 54, p. 273-6, nov./dez., 1928.

SANTOS, Leopoldo Luiz. O Contador - O Actuário - O Auditor. Revista Paulista de Contabilidade, v. 121/122, p. 173-6, jul./ago., 1934.

SCHWACKE, Osmar. Forma e Conteúdo dos Relatórios de Auditores Independentes. Revista Paulista de Contabilidade, v. 431, p. $35,1970$.

TOLEDO FILHO, Jorge Ribeiro, A Evolução do Pensamento Contábil, São Paulo, 1980. 115 p. Dissertação. (Mestrado em Controladoria e Contabilidade) - Faculdade de Economia, Administração e Contabilidade da Universidade de São Paulo.

NOTA:

Endereços dos autores:

ÁLVARO RICARDINO

Centro Universitário Fundação Santo André

Av. Príncipe de Gales, 821 - Príncipe de Gales

Santo André - SP

09060-650

L.NELSON DE CARVALHO

FEA/USP

Av. Prof. Luciano Gualberto, 908 - Butantã

São Paulo - SP

05588-900 